\title{
O conceito de corporalidade em periódicos da Educação Física brasileira: uma revisão integrativa
}

\section{RESUMO}

Este texto tem como objetivo investigar o uso do termo corporalidade e suas definições em periódicos brasileiros relacionados à Educação Física. Foram selecionados artigos de revistas com a classificação Web Qualis de 2013 a 2016, relacionadas ao campo de conhecimento da Educação Física entre os extratos A-2 e B-2. A metodologia utilizada constituiu-se uma revisão integrativa com análise quanti-qualitativa. $\mathrm{O}$ que se pôde perceber foi que a maioria dos textos $(54,55 \%)$ não apresenta uma definição específica. Entretanto, os demais apresentam concepções que podem ser separadas em três categorias/abordagens: 1) Corporalidade como construção histórica e social vinculada ao poder, à linguagem e ao trabalho; 2) Processo de comunicação e; 3) Relação sociocultural manifesta na linguagem. Concluiu-se que o termo não possui definiçõos unívocas, o que demanda novos estudos.

PALAVRAS-CHAVE: Corporalidade; Educação física; Periódicos
Milena de Lourdes Gomes Kirsten Professora Mestra Instituto Federal Goiano milena.kirsten@ifgoiano.edu.br https://orcid.org/0000-0003-3460-434X

Luciane Silva Avelar Mestranda Educação Física Universidade Federal de Goiás, Goiânia, Brasil

lulauavelar@gmail.com https://orcid.org/0000-0003-0898-9442

Tadeu João Ribeiro Baptista Professor Doutor

Universidade Federal Rio Grande do Norte, Departamento de Educação Física tadeujrbaptista@yahoo.com.br http://orcid.org/0000-0001-5140-2032 


\title{
The corporality concept in brazilian Physical Education journals: an integrative review
}

\begin{abstract}
This text aims to investigate the use of the term corporality and definitions in Brazilian journals related to Physical Education. Articles from journals classified as WebQualis from 2013 to 2016 were selected, related to the Physical Education knowledge field between extracts A-2 and B-2. The methodology used consisted of an integrative review with quantitative-qualitative analysis. What could be seen was that most texts $(54.55 \%)$ do not have a specific definition. However, the others present concepts that can be separated into three categories/approaches: 1) Corporality as a historical and social construction linked to power, language and work; 2) Communication process and; 3) Sociocultural relationship manifested in language. It was concluded that the term does not have univocal definitions, which requires further studies.
\end{abstract}

KEYWORDS: Corporality; Physical education; Journals

\section{El concepto de corporalidad en revistas de Educación Física brasileñas: una revisión integrativa}

\section{RESUMEN}

Este texto tiene como objetivo investigar el uso del término corporalidad y sus definiciones en revistas brasileñas relacionadas con la Educación Física. Se seleccionaron artículos de revistas clasificadas como WebQualis de 2013 a 2016, relacionadas con el campo de conocimiento de la Educación Física entre los extractos A-2 y B-2. La metodología utilizada consistió en una revisión integradora con análisis cuantitativo-cualitativo. Lo que se pudo ver fue que la mayoría de los textos $54.55 \%$ no tienen una definición específica. Sin embargo, los demás presentan conceptos que se pueden separar en tres categorías / enfoques: 1) Corporalidad como construcción histórica y social ligada al poder, el lenguaje y el trabajo; 2) Proceso de comunicación y; 3) Relación sociocultural manifestada en el lenguaje. Se concluyó que el término no tiene definiciones unívocas, lo que requiere más estudios.

PALABRAS-CLAVE: Corporalidad; Educación física; Publicaciones periódicas 


\section{INTRODUÇÃO}

O final do século XX foi permeado por debates em torno do campo de conhecimento da Educação Física reconhecido pelos acadêmicos e profissionais desta área como um período de crise e questionamentos. Naquele momento, o debate sobre o papel social dela, as suas vinculações, a relação com o corpo discente, objetivos, conteúdos, metodologias e processos de avaliação adotados até então, foram postos em xeque.

Entre os inúmeros temas de debate, um deles começou a tomar forma de maneira mais explícita: as reflexões sobre o corpo. Alguns livros e autores como os publicados por Codo e Senne (1984); Santin (2003); Medina (2009; 2010), questionaram essa compreensão e, de certo modo, apontaram para outras formas de reflexão e concepções sobre o corpo. Neste sentido, este debate assumiu aspectos que o aproximaram das Ciências Humanas, da Filosofia e das Artes.

Os conceitos a respeito do entendimento sobre o corpo se estabelecem desde a antiguidade com uma série de filósofos, entre os quais é possível citar Platão e Aristóteles na Antiguidade até se chegar aos dias atuais (ZOBOLI, 2012). Neste contexto uma série de professores passaram a considerar que o termo "corpo" era insuficiente para se compreender a realidade do alunado, uma vez que, ao se olhar para o corpo, pode se remeter à ideia de um corpo morto, como afirmam Adorno e Horkheimer (1985).

Não se pode mais converter o corpo físico (Körper) no corpo vivo (Leib). Ele permanece um cadáver, por mais exercitado que seja. A transformação em algo morto, que se anuncia em seu nome, foi uma parte desse processo perene que transformava a natureza em matéria e material. As obras da civilização são o produto da sublimação, desse amor-ódio adquirido pelo corpo e pela terra, dos quais a dominação arrancou todos os homens (ADORNO; HORKHEIMER, 1985, p. 218).

Assim sendo, vários professores nos anos 1980, procuram identificar e constituir um outro conceito que se aproximasse da ideia deste corpo vivo, expressão da totalidade humana como menciona Marzano-Parisoli (2004, p. 45): “Cada indivíduo existe enquanto corpo animado, e seu corpo nunca é apenas um corpo-objeto-orgânico (Körper), estudado pela ciência, mas é também um corpo-sujeito (Leib), próprio a cada pessoa [...]”. Na busca da compreensão deste corpo-sujeito, negando a ideia de um corpo-objeto-orgânico, vários professores passaram a adotar o termo corporalidade (CL). Ao discutir a concepção de CL, Oliveira (2014, p. 155-156) diz:

[...] essa noção só faz sentido na sua materialidade radical, nas formas de se comunicar (linguagem), de produção da vida (trabalho) e de gestão do interesse 
público (que envolve poder), formas que dizem respeito à vida em comum, mas que têm alijado da vida política, da dimensão pública, enormes parcelas da sociedade brasileira). Esse diagnóstico a distancia de qualquer noção idealista, inclusive a noção de corporeidade, no modo como circulou entre nós, pelo entendimento que muito autores conceberam esse conceito de uma maneira excessivamente abstrata, por vezes até metafísica. Ou seja, corporalidade não é uma maneira diferente de dizer o mesmo. Antes, como noção teórica, pretende refletir, por meio das manifestações corporais, sobre os problemas que afligem homens e mulheres vivendo em uma sociedade no instante de cada um dos seus encontros com os outros, consigo ou com o mundo no qual partilham as suas experiências (Grifo do autor).

Apesar de CL e corporeidade serem considerados sinônimos na língua portuguesa e alguns intelectuais da área reafirmarem isso (NÓBREGA, 2010), a maneira como Santin (2014), trata a ideia de corporeidade é distinta daquela apresentada por Oliveira (2014) para CL. Por outro lado, existem estudos que procuram apontar a diferença entre estes termos como é o caso do trabalho de Soares; Kaneko e Gleyse (2019). Ademais, o termo corporeidade tem sido usado de maneira significativa dentro da tradição fenomenológica de Merleau-Ponty, como se pode ver nas produções de Moreira e Simões (2016); Nóbrega (2010; 2018); Santin (2003; 2014); Soares; Kaneko; e Gleyse (2019).

Oliveira (2014, p. 153, grifo do autor), ainda comenta: “[...] em termos acadêmicos corporalidade aparece em língua espanhola com mais frequência que em português. Não raro ela acompanha reflexões sobre o corpo no âmbito da Antropologia e da Filosofia, alguns poucos na Educação Física [...]”. Deste modo, a finalidade deste texto foi investigar, por meio de uma revisão integrativa, o uso do termo CL, suas definições (ou ausência delas) em periódicos brasileiros relacionados à Educação Física.

\section{METODOLOGIA}

Este é um estudo de base quanti-qualitativa, caracterizado como uma revisão integrativa (MENDES; SILVEIRA; GALVÃO, 2008). Para selecionar o corpus da pesquisa, seguimos a classificação do WebQualis adotada como referência para o quadriênio 2013-2016 ${ }^{1}$, presente também na plataforma sucupira ${ }^{2}$, (com acesso em 16 fev. 2021), devido ao fato de este estrato adotar separações por áreas específicas. Desse modo, foram selecionadas revistas brasileiras da

\footnotetext{
${ }^{1}$ Apesar de já estar circulando uma novo WebQualis, com um estrato único, este documento ainda não foi oficializado. Deste modo, na data da coleta de dados desta pesquisa (primeiro semestre de 2020), optamos por usar o documento de referência para o quadriênio 2013-2016. Além disso, o "novo Qualis" que vem circulando, aponta todas as revistas brasileiras da Educação Física em estratos inferiores (B), aspecto muito prejudicial para a produção de conhecimento do campo, o que não é objeto de discussão deste texto.

${ }^{2} \mathrm{https} / / /$ sucupira.capes.gov.br/sucupira/public/consultas/coleta/veiculoPublicacaoQualis/listaConsultaGeralPeriodicos.js f
} 
Educação Física, as quais apresentam temas relacionados às temáticas deste campo de conhecimento que estivessem nos estratos entre A-2 e B-2, uma vez que, não se encontraram revistas A-1 publicadas no país, bem como, ao mesmo tempo, foi possível ampliar o número de periódicos. Além disso, esta estratificação permitiu identificar as revistas com os níveis de Qualis mais altos de acordo com a Coordenação de Aperfeiçoamento de Pessoal de Nível Superior (CAPES) que coordena e avalia os programas de pós-graduação no Brasil. Ademais, foram selecionadas as revistas que tivessem acesso gratuito e os textos na íntegra disponíveis on-line para permitir a leitura e análise dos artigos.

Para a seleção dos artigos usou-se como termo de busca a palavra "corporalidade", uma vez que, o objetivo desta pesquisa é analisar como este descritor é definido nos periódicos da Educação Física brasileira, haja vista, existirem divergências em relação ao seu uso. Os artigos selecionados deveriam apresentar a palavra no título, no resumo e/ou nas palavras-chave. Não se estabeleceu um critério temporal para a seleção, pois, assim foi possível identificar nos periódicos selecionados, quando o termo apareceu pela primeira vez nas revistas científicas.

Desse modo, é apresentado na tabela 1 as Revistas identificadas, seu estrato no WebQualis utilizado, o link de acesso e o número de textos identificados em cada um dos periódicos brasileiros de Educação Física encontrados.

Tabela1: Periódicos Brasileiros de Educação Física identificados pelo estrato na Plataforma Sucupira (20132016) e o número de textos identificados em cada um deles

\begin{tabular}{|c|c|c|c|c|}
\hline ISSN & Título & $\begin{array}{c}\text { Estrato } \\
\text { Qualis }\end{array}$ & Link da Revista & $\begin{array}{l}N^{0} \text { de } \\
\text { Textos }\end{array}$ \\
\hline $\begin{array}{l}1982- \\
8918\end{array}$ & $\begin{array}{l}\text { Movimento } \\
\text { Online) }\end{array}$ & A-2 & $\begin{array}{l}\text { https://seer.ufrgs.br/Movimen } \\
\text { to }\end{array}$ & 2 \\
\hline $\begin{array}{l}1980- \\
6574\end{array}$ & $\begin{array}{l}\text { Motriz: } \quad \text { Revista de } \\
\text { Educação Física (Online) }\end{array}$ & B-1 & $\begin{array}{l}\text { http://www.scielo.br/scielo.ph } \\
\text { p?script=sci_serial\&pid=198 } \\
\underline{\text { 0-6574\&lng=en\&nrm=iso }}\end{array}$ & 0 \\
\hline $\begin{array}{l}\text { 1980- } \\
0037\end{array}$ & $\begin{array}{lr}\text { Revista Brasileira } & \text { de } \\
\text { Cineantropometria } & \text { e } \\
\text { Desempenho Humano } & \end{array}$ & B-1 & $\begin{array}{l}\text { http://www.scielo.br/scielo.ph } \\
\text { p?script=sci_serial\&pid=198 } \\
\underline{\text { 0-0037\&lng=en\&nrm=iso }}\end{array}$ & 0 \\
\hline $\begin{array}{l}2179 . \\
3255\end{array}$ & $\begin{array}{lcr}\text { Revista } & \text { Brasileira } & \text { de } \\
\text { Ciências } & \text { do } & \text { Esporte } \\
\text { (Online) } & & \\
\end{array}$ & B-1 & $\begin{array}{l}\text { http://www.scielo.br/scielo.ph } \\
\text { p?script=sci_serial\&pid=010 } \\
\underline{1-3289 \& \operatorname{lng}=\text { pt\&nrm }=\text { iso }}\end{array}$ & 3 \\
\hline $\begin{array}{l}1981- \\
4690\end{array}$ & $\begin{array}{l}\text { Revista Brasileira de } \\
\text { Educação Física e Esporte }\end{array}$ & B-1 & $\begin{array}{l}\text { http://www.scielo.br/scielo.ph } \\
\text { p?script=sci_serial\&pid=180 } \\
\text { 7-5509\&lng=en\&nrm=iso }\end{array}$ & 0 \\
\hline $\begin{array}{l}1983- \\
3083\end{array}$ & $\begin{array}{l}\text { Revista da Educação Física } \\
\text { (UEM. Online) }\end{array}$ & B-1 & $\begin{array}{l}\text { http://www.scielo.br/scielo.ph } \\
\text { p?script=sci_serial\&pid=198 } \\
\text { 3-3083\&lng=en\&nrm=iso }\end{array}$ & 0 \\
\hline $\begin{array}{l}\text { 1981- } \\
3171\end{array}$ & $\begin{array}{l}\text { Licere (Centro de Estudos } \\
\text { de Lazer e Recreação. }\end{array}$ & B-2 & $\begin{array}{l}\text { https://periodicos.ufmg.br/ind } \\
\text { ex.php/licere/index }\end{array}$ & 2 \\
\hline
\end{tabular}




\begin{tabular}{|c|c|c|c|c|}
\hline & Online) & & & \\
\hline $\begin{array}{l}2175- \\
8042\end{array}$ & $\begin{array}{l}\text { Motrivivência } \\
\text { (Florianópolis) }\end{array}$ & B-2 & $\frac{\text { https://periodicos.ufsc.br/inde }}{\text { x.php/motrivivencia }}$ & 4 \\
\hline $\begin{array}{l}1980- \\
6183\end{array}$ & Pensar a Prática (Online) & B-2 & https://www.revistas.ufg.br/fe & 5 \\
\hline $\begin{array}{l}2317- \\
1634\end{array}$ & $\begin{array}{l}\text { Revista Brasileira de } \\
\text { Atividade Física e Saúde }\end{array}$ & B-2 & https://rbafs.org.br/RBAFS & 0 \\
\hline $\begin{array}{l}\text { 0103- } \\
1716\end{array}$ & $\begin{array}{l}\text { Revista Brasileira de } \\
\text { Ciência e Movimento }\end{array}$ & B-2 & $\begin{array}{l}\text { https://portalrevistas.ucb.br/in } \\
\text { dex.php/RBCM }\end{array}$ & 0 \\
\hline
\end{tabular}

Fonte: Elaboração Própria

De acordo com os dados apresentados foram identificados 11 periódicos brasileiros entre os estratos A-2 a B-2, sendo uma revista A-2; cinco revistas B-1 e; cinco periódicos B-2. Nesta amostragem, sem se considerar o ano de publicação, seis revistas não apresentaram nenhum texto relacionado com a CL, desde sua criação, sendo elas: Motriz: Revista de Educação Física (Online); Revista Brasileira de Cineantropometria e Desempenho Humano; Revista Brasileira de Educação Física e Esporte; Revista da Educação Física (UEM. Online); Revista Brasileira de Atividade Física e Saúde; Revista Brasileira de Ciência e Movimento.

Nos demais periódicos foi possível identificar no total 16 textos ao se usar a palavra-chave estabelecida. Todavia, em cinco deles, a palavra de referência não era encontrada no título, no resumo e/ou nas palavras-chave, aparecendo apenas no corpo do texto. Deste modo, estes artigos, fugiram do critério de seleção estabelecido e, por isso, foram eliminados permitindo a elaboração da tabela 2 .

Tabela 2: Número de Artigos identificados e analisados por Revista

\begin{tabular}{llcc}
\hline ISSN & Revista & $\begin{array}{c}\text { Artigos } \\
\text { Identificados }\end{array}$ & $\begin{array}{c}\text { Artigos } \\
\text { Analisados* }\end{array}$ \\
\hline $\mathbf{1 9 8 2}-$ & Movimento (UFRGS. Online) & 2 & 1 \\
$\mathbf{8 9 1 8}$ & & 3 & 3 \\
\hline $\mathbf{2 1 7 9 -}$ & Revista Brasileira de Ciências do Esporte (Online) & & 1 \\
$\mathbf{3 2 5 5}$ & & 2 & 3 \\
\hline $\mathbf{1 9 8 1 -}$ & Licere (Centro de Estudos de Lazer e Recreação. & \\
$\mathbf{3 1 7 1}$ & Online) & 4 & 3 \\
\hline $\mathbf{2 1 7 5}-$ & Motrivivência (Florianópolis) & 5 & 11 \\
\hline $\mathbf{8 0 4 2}$ & Pensar a Prática (Online) & & 16 \\
\hline $\mathbf{6 1 8 3}$ & & & 3 \\
\hline Total & & & \\
\hline
\end{tabular}

* Só foram analisados os artigos que possuíam o termo corporalidade no Título, Resumo ou Palavra-Chave. Os textos que apresentavam CL no corpo do texto, foram eliminados.

Fonte: Elaboração Própria. 
Desse modo, todos os artigos selecionados foram lidos na íntegra e em seguida, procurou-se identificar como cada artigo definia CL. Após a identificação, o termo foi agrupado por categorias, conforme se apresenta a seguir. Para descrever o processo de maneira esquemática apresenta-se a figura 1 .

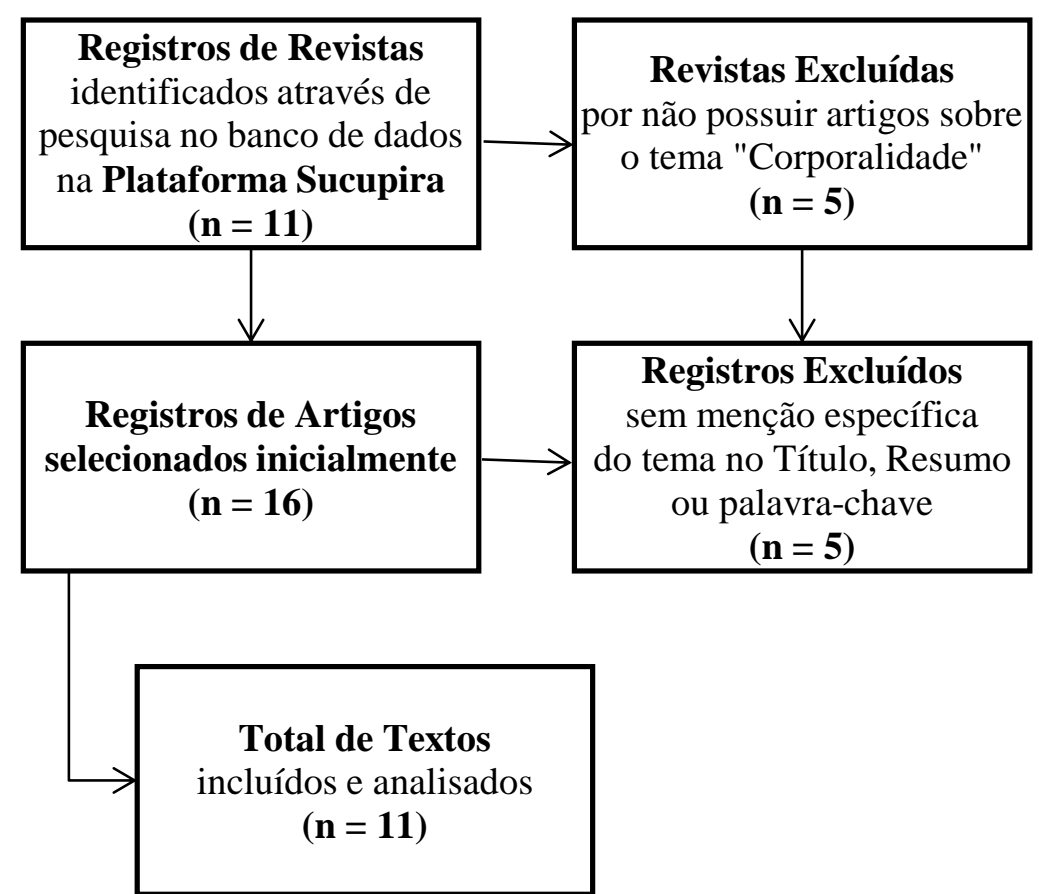

Figura 1: Fluxo de informação da revisão integrativa Fonte: Elaboração Própria

\section{RESULTADOS E DISCUSSÃO}

Para iniciar a apresentação, análise e discussão dos resultados, será apresentado o nome dos artigos, autores, volume, número (quando houver), páginas e ano de publicação de acordo com as Revistas, nas quais foram identificados os artigos.

Também cabe destacar neste ponto que os textos que tratam da corporalidade e que foram analisados foram publicados entre 1998/1999 - o primeiro identificado - e 2018 - o mais recente. Isso demonstra que apesar de haver um período de 20 anos entre a primeira e a última publicação sobre a CL nos periódicos analisados, o tema foi pouco explorado, considerando-se que; a) se for estabelecida a média, haverá menos de um artigo publicado por ano e; b) nenhum novo artigo foi publicado nos últimos três anos (2018-2021). 
Quadro 1: Distribuição dos artigos de acordo com a revista, o volume (v), o número (n), as páginas de publicação (p), o ano, o título e a autoria.

\begin{tabular}{|c|c|c|c|c|c|c|}
\hline Revista & $\mathbf{v}$ & $\mathbf{n}$ & $\mathbf{p}$ & Ano & Título & Autores \\
\hline $\begin{array}{l}\text { Movimento } \\
\text { (UFRGS. } \\
\text { Online) }\end{array}$ & 12 & 1 & $11-29$ & 2006 & $\begin{array}{l}\text { Mulheres no Esporte: } \\
\text { corporalidades e } \\
\text { subjetividades }\end{array}$ & Miriam Adelman \\
\hline \multirow[t]{3}{*}{$\begin{array}{ll}\text { Revista } & \\
\text { Brasileira } & \text { de } \\
\text { Ciências } & \text { do } \\
\text { Esporte } & \\
\text { (Online) } & \end{array}$} & 33 & 2 & $\begin{array}{l}375- \\
390\end{array}$ & 2011 & $\begin{array}{c}\text { O que podemos aprender } \\
\text { com as crianças } \\
\text { indígenas? } \\
\text { Aproximações da } \\
\text { antropologia da criança } \\
\text { às noções de infância, } \\
\text { cultura e movimento na } \\
\text { educação física }\end{array}$ & Iracema Munarim \\
\hline & 38 & 2 & $\begin{array}{l}194- \\
200\end{array}$ & 2016 & $\begin{array}{l}\text { La sociogénesis del } \\
\text { modo de corporalidad } \\
\text { moderno. El problema } \\
\text { del objeto en las } \\
\text { investigaciones sobre } \\
\text { cuerpo a partir de la } \\
\text { teoría crítica reflexiva }\end{array}$ & $\begin{array}{c}\text { Emiliano } \\
\text { Gambarotta }\end{array}$ \\
\hline & 39 & 3 & $\begin{array}{l}240- \\
246\end{array}$ & 2017 & $\begin{array}{c}\text { El cuerpo del } \\
\text { postestructuralismo. } \\
\text { Problemas } \\
\text { epistemológicos a partir } \\
\text { de la perspectiva de J. } \\
\text { Butler }\end{array}$ & $\begin{array}{c}\text { Emiliano } \\
\text { Gambarotta }\end{array}$ \\
\hline $\begin{array}{l}\text { Licere (Centro } \\
\text { de Estudos de } \\
\text { Lazer } \\
\text { Recreação. } \\
\text { Online) }\end{array}$ & 12 & 2 & $1-23$ & 2009 & $\begin{array}{l}\text { Representações de corpo } \\
\text { e movimento no } \\
\text { ciberespaço: notas de um } \\
\text { estudo etnográfico no } \\
\text { jogo Second Life }\end{array}$ & $\begin{array}{c}\text { Rogério Santos } \\
\text { Pereira; Maurício } \\
\text { Roberto da Silva; } \\
\text { Giovani de Lorenzi } \\
\text { Pires }\end{array}$ \\
\hline $\begin{array}{l}\text { Motrivivência } \\
\text { (Florianópolis) }\end{array}$ & $\mathrm{NI}^{*}$ & 15 & $1-5$ & 2000 & Políticas do Corpo & $\begin{array}{l}\text { Carlos Alberto } \\
\text { Libânio Christo } \\
\text { (Frei Betto) }\end{array}$ \\
\hline \multirow[t]{2}{*}{$\begin{array}{l}\text { Motrivivência } \\
\text { (Florianópolis) }\end{array}$} & $\begin{array}{c}\text { XXI } \\
\text { II }\end{array}$ & 37 & $51-68$ & 2011 & $\begin{array}{l}\text { As crianças como autoras } \\
\text { da significação da } \\
\text { educação física }\end{array}$ & $\begin{array}{l}\text { Rubens Machado; } \\
\text { Bruno Fagundes; } \\
\text { Fabiano Weber da } \\
\text { Silva }\end{array}$ \\
\hline & 30 & 54 & $\begin{array}{l}295- \\
307\end{array}$ & 2018 & $\begin{array}{c}\text { Estrutura e função social } \\
\text { da atividade esportiva e o } \\
\text { processo de apropriação } \\
\text { da cultura: contribuições } \\
\text { para a atividade de } \\
\text { ensino na educação física } \\
\text { escolar }\end{array}$ & $\begin{array}{l}\text { Antonio Leonan } \\
\text { Alves Ferreira }\end{array}$ \\
\hline $\begin{array}{l}\text { Pensar } \\
\text { Prática } \\
\text { (Online) }\end{array}$ & 2 & NI & $\begin{array}{l}119- \\
135\end{array}$ & $\begin{array}{l}1998 / \\
1999\end{array}$ & $\begin{array}{c}\text { Existe espaço para o } \\
\text { ensino de educação física } \\
\text { na escola básica? }\end{array}$ & $\begin{array}{l}\text { Marcus Aurélio } \\
\text { Taborda de } \\
\text { Oliveira } \\
\end{array}$ \\
\hline
\end{tabular}




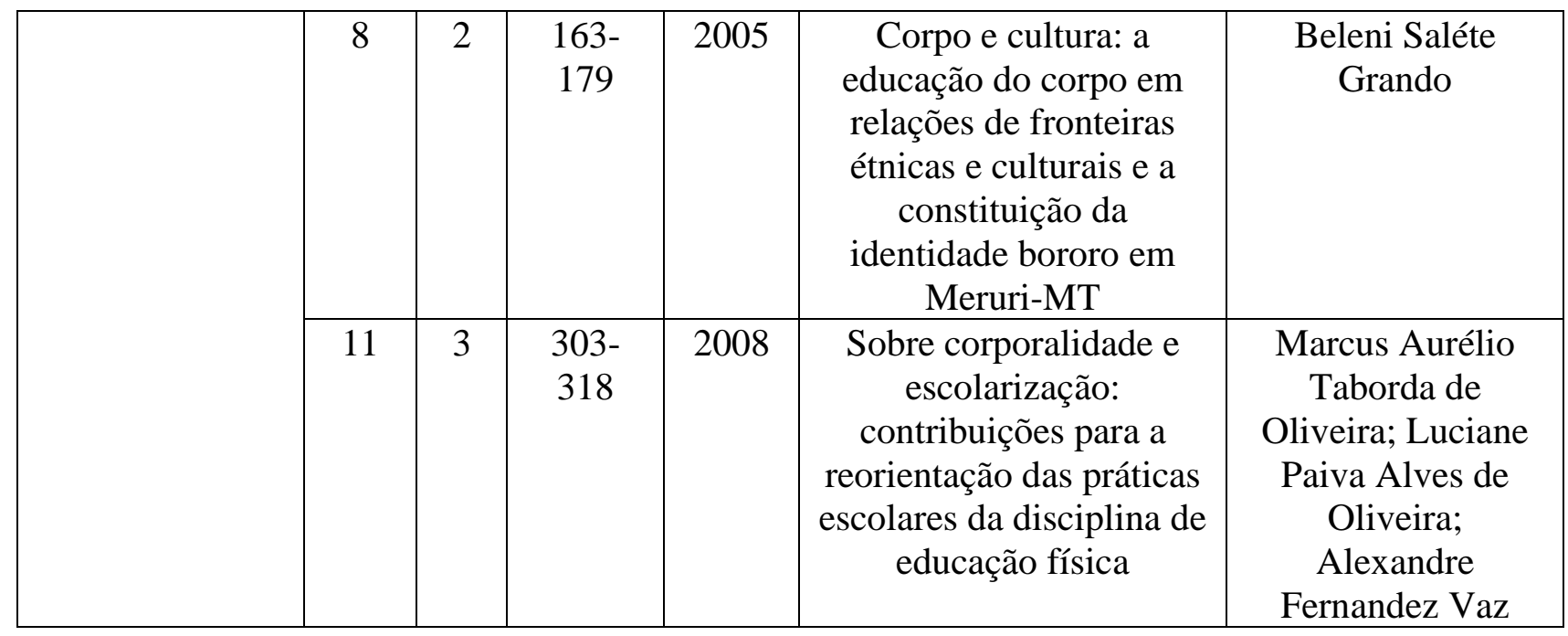

*NI = Não informado.

Fonte: Elaboração Própria

O primeiro aspecto que se pretende destacar é o fato de que o termo "corporalidade" aparece pela primeira vez, nos textos analisados, na Revista Pensar a Prática e foi escrito por Marco Aurélio Taborda de Oliveira (OLIVEIRA, 1998/1999). Outro ponto de destaque é que além de ser o primeiro autor a usar a expressão CL, ele também foi o autor que mais discutiu o tema (OLIVEIRA, 1998/1999; OLIVEIRA; OLIVEIRA; VAZ, 2008), juntamente com Emiliano Gambarotta (2016; 2017).

Um segundo enfoque a ser discutido diz respeito aos autores, à titulação, o vínculo institucional e o estado ou país de residência. Estes dados estão descritos no Quadro 2.

Quadro 2: Nome dos autores, Titulação, Vínculo Institucional, Naturalidade

\begin{tabular}{|l|l|l|l|l|}
\hline $\mathbf{N}^{\mathbf{0}}$ & \multicolumn{1}{|c|}{ Autor } & Titulação & \multicolumn{1}{|c|}{ Instituição } & Estado/País \\
\hline 01 & Miriam Adelman & Doutora & $\begin{array}{l}\text { Departamento de Ciências Sociais da } \\
\text { Universidade Federal do Paraná }\end{array}$ & Paraná \\
\hline 02 & $\begin{array}{l}\text { Emiliano } \\
\text { Gambarotta }\end{array}$ & Doutor & $\begin{array}{l}\text { Consejo Nacional de Investigaciones } \\
\text { Científicas y Técnicas (Conicet), } \\
\text { Universidad Nacional de La Plata (UNLP), } \\
\text { Instituto de Investigaciones en Humanidades } \\
\text { y Ciencias (IdIHCS) }\end{array}$ & Argentina \\
\hline 03 & $\begin{array}{l}\text { Iracema } \\
\text { Munarim }\end{array}$ & Mestre & $\begin{array}{l}\text { Programa de Pós-Graduação em Educação da } \\
\text { Universidade Federal de Santa Catarina }\end{array}$ & Santa \\
\hline Emiliano & Doutor & $\begin{array}{l}\text { Instituto de Investigaciones en Humanidades } \\
\text { y Ciencias Sociales (IdIHCS), Universidad } \\
\text { Nacional de La Plata (UNLP); Facultad de } \\
\text { Humanidades y Ciencias de la Educación; } \\
\text { Investigador Asistente del Conicet }\end{array}$ & Argentina \\
\hline
\end{tabular}




\begin{tabular}{|c|c|c|c|c|}
\hline 05 & $\begin{array}{l}\text { Rogério Santos } \\
\text { Pereira }\end{array}$ & Mestre & $\begin{array}{l}\text { Integrante do Grupo de Estudos Observatório } \\
\text { da Mídia Esportiva/LaboMídia - } \\
\text { CDS/UFSC, Professor da Faculdade do } \\
\text { Futuro - Manhuaçu/MG. }\end{array}$ & Minas Gerais \\
\hline 06 & $\begin{array}{l}\text { Maurício } \\
\text { Roberto da Silva }\end{array}$ & Pós-Doutor & Professor do DEF/CDS/UFSC. & $\begin{array}{l}\text { Santa } \\
\text { Catarina }\end{array}$ \\
\hline 07 & $\begin{array}{l}\text { Giovani de } \\
\text { Lorenzi Pires }\end{array}$ & Doutor & $\begin{array}{llr}\text { Professor do DEF/CDS/UFSC } & \text { e } \\
\text { PPGEF/UFSC, coordenador } & \text { do } \\
\text { LaboMídia/CDS/UFSC e do Grupo de } \\
\text { Estudos Observatório } \\
\text { Esportiva/UFSC }\end{array}$ & $\begin{array}{l}\text { Santa } \\
\text { Catarina }\end{array}$ \\
\hline 08 & $\begin{array}{l}\text { Antonio Leonan } \\
\text { Alves Ferreira }\end{array}$ & Doutor & $\begin{array}{l}\text { Instituto Federal de Educação, Ciência e } \\
\text { Tecnologia Baiano (IFBA) }\end{array}$ & Bahia \\
\hline 09 & $\begin{array}{l}\text { Carlos A. L. } \\
\text { Christo (Frei } \\
\text { Betto) }\end{array}$ & Graduação & Universidade Federal de Santa Catarina & $\begin{array}{l}\text { Santa } \\
\text { Catarina }\end{array}$ \\
\hline 10 & Rubens Machado & Graduando & UNIV ALI/ Biguaçu; & $\begin{array}{l}\text { Santa } \\
\text { Catarina }\end{array}$ \\
\hline 11 & Bruno Fagundes & Graduando & UNIVALI/Biguaçu; & $\begin{array}{l}\text { Santa } \\
\text { Catarina }\end{array}$ \\
\hline 12 & $\begin{array}{l}\text { Fabiano Weber } \\
\text { da Silva }\end{array}$ & Mestre & UNIVALI/Biguaçu & $\begin{array}{l}\text { Santa } \\
\text { Catarina }\end{array}$ \\
\hline 13 & $\begin{array}{l}\text { Marcus Aurélio } \\
\text { Taborda de } \\
\text { Oliveira }\end{array}$ & Doutor & $\begin{array}{l}\text { Professor do Programa de Pós-Graduação em } \\
\text { Educação/Universidade Federal do Paraná e } \\
\text { pesquisador CNPq }\end{array}$ & Paraná \\
\hline 14 & $\begin{array}{l}\text { Luciane Paiva } \\
\text { Alves de Oliveira }\end{array}$ & Doutora & $\begin{array}{l}\text { Professora do Setor de Educação da } \\
\text { Universidade Federal do Paraná }\end{array}$ & Paraná \\
\hline 15 & $\begin{array}{l}\text { Alexandre } \\
\text { Fernandez Vaz }\end{array}$ & Doutor & $\begin{array}{l}\text { Professor da Universidade Federal de Santa } \\
\text { Catarina e pesquisador CNPq. }\end{array}$ & $\begin{array}{l}\text { Santa } \\
\text { Catarina }\end{array}$ \\
\hline 16 & $\begin{array}{l}\text { Marcus Aurélio } \\
\text { Taborda de } \\
\text { Oliveira }\end{array}$ & Doutor & Universidade Federal do Paraná & Paraná \\
\hline 17 & $\begin{array}{l}\text { Beleni Saléte } \\
\text { Grando }\end{array}$ & Doutora & $\begin{array}{l}\text { Universidade do Estado de Mato Grosso, } \\
\text { Campus de Cáceres, e membro permanente } \\
\text { do Programa de Pós-Graduação em Educação } \\
\text { da Faculdade de Educação }\end{array}$ & Mato Grosso \\
\hline
\end{tabular}

Fonte: Elaboração Própria 
No Quadro 2, é possível identificar que ao todo, estão presentes 17 autores, sendo que alguns deles, como foi mencionado anteriormente, aparecem em mais de um artigo sobre o tema. Outro ponto de destaque é a titulação sendo que foi possível identificar nesta produção 11 doutores/doutoras; sendo que um apresenta-se como Pós-Doutor; três mestres, sendo que a autora Iracema Munarim, no momento da publicação do texto informou que era doutoranda; um com graduação e dois graduandos. Neste caso, considerando-se as atuais normas de produção científica, é esperado que haja uma maior quantidade de doutores e doutoras publicando em periódicos indexados, pois, faz parte das normas da Pós-Graduação que os professores demonstrem produtividade para se manterem nos programas de pós-graduação, como demonstram Mafra (2020) e Barata (2019), embora, esta última aponte a necessidade de revisão dos parâmetros de avaliação dos programas de pós-graduação e dos seus docentes.

Outro ponto que pode ser destacado em relação à titulação é que, atualmente, a maioria dos periódicos, procurando melhorar a sua qualidade e indexação, tem indicado como norma da publicação que ao menos um dos autores seja doutor. Assim, neste estudo se verificou que apenas 3 dos 11 artigos analisados (27,27\%), não tinham um doutor como autor ou coautor.

Um exame distinto realizado neste texto, destaca o número de mulheres participantes destes artigos, considerando a duplicidade de autoria nos artigos analisados. Dos 17 autores identificados, quatro eram mulheres $(23,53 \%)$, um fato que vem sendo cada vez mais discutido na ciência brasileira. Sobre este aspecto, Mafra (2020, p. 7) comenta:

[...] tal dado merece análise minuciosa para que se busque melhor compreender a representação de homens e mulheres na pesquisa científica, o impacto da maternidade e outras questões diretamente relacionadas à mulher, bem como a ocorrência de preconceitos e outros fatores diretos ou indiretos em ações tomadas, assumidas ou não, no ambiente acadêmico [...].

Outra apreciação que faz parte do perfil sociodemográfico e que se estabelece como um dos objetivos deste trabalho é a identificação do estado/país de origem das autoras e dos autores. Dos 17 autores e autoras uma é do Mato Grosso (5,88\%); um da Bahia (5,88\%), dois de La Plata Argentina (11,76\%), embora seja o mesmo autor; quatro do Paraná $(23,53 \%)$, contando que um dos autores também aparece em dois artigos e; nove de Santa Catarina (52,94\%). Destaca-se ainda que 64,71\% dos trabalhos sobre a CL analisados, são provenientes da região sul do Brasil, uma região bastante conhecida pela produção do conhecimento. O estudo de Coutinho et al. (2012, p. 499), ao analisar a produção brasileira da Educação Física sobre o cotidiano escolar 
[...] demonstrou uma grande concentração de grupos registrados no $\mathrm{CNPq}$ nos estados das regiões Sul e Sudeste [...]. Acompanhando o mesmo raciocínio, Lüdorf (2002), ao estudar os resumos de teses e dissertações dos cursos de pós-graduação em Educação Física na década de 1990, encontrou uma concentração de $76 \%$ na região Sudeste e $24 \%$ na região Sul [...].

A seguir, será apresentado o Quadro 3, que demonstra de maneira específica as compreensões dos autores sobre a corporalidade nos textos analisados.

Quadro 3: Concepções de corporalidade identificadas nos textos e a autoria dos mesmos.

\begin{tabular}{|c|c|c|}
\hline $\mathbf{N}^{\mathbf{o}}$ & Concepção apresentada & Autoria \\
\hline 01 & Não explicita a concepção de corporalidade utilizada no texto. & $\begin{array}{c}\text { CHRISTO (Frei } \\
\text { Betto), } 2000\end{array}$ \\
\hline 02 & Não explicita a concepção de corporalidade utilizada no texto. & GRANDO, 2005 \\
\hline 03 & Não explicita a concepção de corporalidade utilizada no texto. & ADELMAN, 2006. \\
\hline 04 & Não explicita a concepção de corporalidade utilizada no texto. & MUNARIM, 2011. \\
\hline 05 & Não explicita a concepção de corporalidade utilizada no texto. & $\begin{array}{l}\text { GAMBAROTTA, } \\
2016 .\end{array}$ \\
\hline 06 & Não explicita a concepção de corporalidade utilizada no texto. & $\begin{array}{l}\text { GAMBAROTTA, } \\
2017 .\end{array}$ \\
\hline 07 & $\begin{array}{l}\text { Ao conjunto de práticas corporais do homem, sua expressão criativa, } \\
\text { seu reconhecimento consciente e sua possibilidade de comunicação e } \\
\text { interação na busca da humanização das relações dos homens entre si } \\
\text { e com a natureza. A corporalidade se consubstancia na prática social } \\
\text { a partir das relações de linguagem, poder e trabalho, estruturantes da } \\
\text { sociedade. }\end{array}$ & $\begin{array}{c}\text { OLIVEIRA, } \\
\text { 1998/1999, p. } 131\end{array}$ \\
\hline 08 & $\begin{array}{l}\text { A corporalidade, entendida como a expressão criativa e consciente } \\
\text { do conjunto das manifestações corporais historicamente produzidas, } \\
\text { as quais pretendem possibilitar a comunicação e a interação de } \\
\text { diferentes indivíduos com eles mesmos, com os outros, com o seu } \\
\text { meio social e natural. Essas manifestações baseiam-se no diálogo } \\
\text { entre diferentes indivíduos, em um contexto social organizado em } \\
\text { torno das relações de poder, linguagem e trabalho. }\end{array}$ & $\begin{array}{l}\text { OLIVEIRA; } \\
\text { OLIVEIRA; VAZ, } \\
\text { 2008, p. } 306\end{array}$ \\
\hline 09 & $\begin{array}{l}\text { “[...], a corporalidade implícita no avatar possui uma posição de } \\
\text { destaque nos processos da comunicação associada ao jogo". }\end{array}$ & $\begin{array}{l}\text { PEREIRA; SILVA; } \\
\text { PIRES, 2009, p. } 14\end{array}$ \\
\hline 10 & $\begin{array}{l}\text { "[...] entendemos que pode ser entendido como corporalidade, desde } \\
\text { que se considere o sujeito sendo um corpo unitário produtor de } \\
\text { cultura, desta forma, corporalidade como a vivência dos frutos da } \\
\text { cultura corporal. Em outras palavras, a satisfação e o prazer praticar } \\
\text { os frutos da cultura corporal; uma forma ampla de linguagem, ou, }\end{array}$ & $\begin{array}{l}\text { MACHADO; } \\
\text { FAGUNDES; SILVA, } \\
2011, \text { p. } 60\end{array}$ \\
\hline
\end{tabular}




\begin{tabular}{|c|c|c|}
\hline & $\begin{array}{l}\text { comunicação e expressão geral do sujeito que é influenciada e } \\
\text { influencia suas manifestações e relações sócio-culturais". }\end{array}$ & \\
\hline 11 & $\begin{array}{l}\text { "Assim, podemos afirmar que a corporalidade humana é um objeto } \\
\text { histórico, é um "ato de nascimento que se supera" (MARX, 2007). } \\
\text { Por outro lado, podemos também afirmar que os animais possuem } \\
\text { corporalidade, no entanto, as leis que a determina são puramente } \\
\text { naturais". }\end{array}$ & $\begin{array}{l}\text { FERREIRA, 2018, p. } \\
305\end{array}$ \\
\hline
\end{tabular}

Fonte: Elaboração Própria

Neste momento da crítica, destaca-se o fato de que os textos de Christo (FREI BETTO, 2000), Grando (2005), Adelman (2006), Munarim (2011), Gambarotta (2016; 2017) não apresentam uma concepção clara de corporalidade, apesar de poder identificar algumas elaborações. Frei Beto (2000) trabalha com a ideia de "corporalidade holística", embora não defina claramente o que isso significa. Grando (2005), por sua vez, cita o termo CL em seu texto quatro vezes. Entretanto, este se refere a um processo histórico de socialização indígena.

O trabalho de Adelman (2006), vincula a CL à construção de identidades e subjetividade como meio de construção dos corpos, mas sem determinações que expressem com clareza ou objetividade o uso do termo e sem deixar nítida a forma como se estabelece essa "construção". Por sua vez, Munarim (2011) relaciona a corporalidade à organização da identidade e subjetividade infantil como sendo um dos mecanismos de apreensão do mundo.

Gambarota $(2016 ; 2017)$, nas duas obras analisadas, apresenta um estudo da socio gênese do corpo a partir da modernidade sem manifestar a ideia que o fez optar pela utilização do termo CL e conecta suas investigações a partir das ideias do pós-estruturalismo. Destarte, foi possível identificar que em seis dos onze trabalhos analisados (54,55\%), os mesmos não definem explicitamente sua compreensão de "corporalidade". Os motivos para isso podem ser inúmeros, contudo, existe a possibilidade que haja uma visão de que não se precisa definir o lugar de fala. Este e outros aspectos precisam ser investigados posteriormente.

Todavia, é importante destacar que quando se trata de um termo para o qual não existe consenso estabelecido na literatura e dentro do campo de conhecimento, entende-se que expressar aquele tema conceitualmente, neste caso a CL, é importante para ajudar os leitores e estudiosos a estabelecerem seus critérios de adoção terminológica.

Ferreira (2018), Machado; Fagundes e Silva (2011), Oliveira; Oliveira e Vaz (2008) e Oliveira (1998-1999) por sua vez, apresentam uma definição de CL ainda que não tenham se preocupado em defender determinada perspectiva epistemológica do termo. Partindo destas análises foi possível identificar que o termo CL não é utilizado a partir de uma única teoria. Entretanto, 
procurou-se estabelecer as principais concepções dos termos. Desse modo, foi possível identificar a corporalidade a partir de três categorias/abordagens centrais:

1. Corporalidade como construção histórica e social vinculada ao poder, à linguagem e ao trabalho;

2. Processo de comunicação;

3. Relação sociocultural manifesta na linguagem.

Na primeira, entende-se a corporalidade como construção histórica e social vinculada ao poder, à linguagem e ao trabalho. Esta categoria/abordagem da CL está presente nos textos de Oliveira (1998/1999); Oliveira; Oliveira e Vaz (2008) e Ferreira (2018). Nestes textos a compreensão da CL é ampla e vem se consolidando juntamente com outros autores que realizam este debate, entre eles Almeida (2004, p. 16-17), quando afirma:

Mas a corporalidade tem, de facto, importância como categoria unificadora da existência humana. Assim, a apropriação social da corporalidade é o protótipo de toda a produção social; a pessoa constituída por uma subjectividade socializada e incorporada é o protótipo de todos os produtos.

Ao trazer a discussão sobre a CL aqui, Almeida (2004) dialoga a partir da teoria antropológica, demonstrando a relevância de se pensar o corpo na sua totalidade. Outra forma de se discutir a corporalidade é:

[...] entendemos esse termo como o processo de expressão do corpo em sua dimensão objetiva, por meio de seu contato com a natureza, ao mesmo tempo, exprimindo a sua perspectiva subjetiva em relação a outros seres humanos. A corporalidade é, desse modo, um processo constituído no contexto histórico das relações sociais contraditórias, mediadas pelas relações de trabalho do modo de produção vigente (BAPTISTA; LEAL, 2018, p. 212).

Em posição distinta da anterior, a corporalidade pode aparecer como processo de comunicação que é explicitamente apresentado pelo trabalho de Pereira; Silva e Pires (2009). No texto analisado é discutida a relação do avatar (representação virtual do corpo) como uma forma de comunicação expressa pelos jogos eletrônicos. Pires et al. (2020) trazem a ideia da relação existente entre o virtual e o real, compreendendo que o corpo, porque não dizer a corporalidade, estabelece relações com a máquina em uma série de semelhanças, ao ponto de, talvez, haver confusão entre o que acontece no real e no virtual. Em certo aspecto, nesta lógica, o virtual é outra forma do real. 
Nos últimos 20 anos, e com a evolução da tecnologia, surgiram dispositivos de visão imersiva com resolução suficiente para que possamos visualizar mundos gerados, e provavelmente testemunharemos uma revolução na interação humana com a tecnologia de realidade virtual e o meio ambiente na próxima década (Shi et al., 2020) [...]. Estas tecnologias, sendo imersivas, condicionam a própria noção de presença, sendo que esta noção é sempre mais forte quando o estímulo sensorial e emocional está presente (PIRES et al., 2020, p. 110).

Por fim, foi possível identificar a categoria/abordagem da corporalidade constituída a partir da relação sociocultural que desponta como uma forma ampla de linguagem. São Machado; Fagundes e Silva (2011) os autores que concebem a corporalidade desse modo. Apesar de este texto trazer a relação sociocultural e constituição da CL por meio da cultura corporal e da própria cultura, ele se diferencia da CL como construção histórica e social vinculada ao poder, à linguagem e ao trabalho, por não se preocupar necessariamente com o trabalho e as relações de poder estabelecidas. Esta discussão se aproxima daquela apresentada por Silva; Silva e Tucunduva (2011, p. 48-49).

A corporalidade, como fenômeno social em sua totalidade, pode ser compreendida por essa relação entre o organismo, a perspectiva subjetiva, a cultura e o ambiente natural onde se constitui, marcando a construção das práticas corporais e de suas técnicas corporais de forma indelével.

No caso desses dois trabalhos, ambos apontam para a corporalidade como uma construção cultural, aproximam-se da lógica presente nos estudos da antropologia, uma vez que, Silva; Silva e Tucunduva (2011), inclusive partem da definição de fato social total e da relação com as técnicas corporais, propostas por Marcel Mauss (2013).

Nesse sentido, pôde-se perceber que os autores que se preocuparam com a definição de corporalidade, compreendem que se trata de um conceito claro e definido, distinto teoricamente de outros termos, como corpo e corporeidade.

\section{CONSIDERAÇÕES FINAIS}

Este texto tem como propósito investigar, o uso do termo corporalidade, suas definições em periódicos brasileiros relacionados à Educação Física. O que pôde ser verificado foi a ausência, na maioria dos textos analisados, de uma especificação da definição de CL. A partir das análises que foram feitas é possível compreender que o debate em torno desta temática ainda carece estudos e aprofundamentos, haja vista, o fato de o termo estar presente na Educação Física brasileira desde 1998/1999 e, ainda assim, mais de 20 anos depois, poucos textos (11 no total), foram publicados usando este termo nos estratos superiores da Educação Física. 
Ao longo da pesquisa, foi possível identificar os autores que mais publicaram sobre o tema nas revistas analisadas, Marcus Aurélio Taborda de Oliveira e Emiliano Gambarotta, um predomínio de doutores, homens e da região sul do Brasil, sobremodo, Santa Catarina. Estes dados demandam outras análises posteriores.

Pensando mais especificamente no foco do estudo, entende-se a necessidade de um rigor teórico e conceitual sobre CL, suas limitações e possibilidades em torno das produções acadêmicas que têm como foco os estudos relacionados à Educação Física. Apesar de, ao analisar os textos ser possível identificar três categorias/abordagens centrais, sendo elas; a) Corporalidade como construção histórica e social vinculada ao poder, à linguagem e ao trabalho; b) Processo de comunicação e; c) Relação sociocultural manifesta na linguagem, evidencia-se que a maioria dos estudos avaliados $(54,55 \%)$ não apresentaram uma definição explícita.

Se a definição de corporalidade aponta para a totalidade corporal do ser humano, a sua constituição histórica social e cultural e se ela se estabelece nas suas relações com a linguagem, o trabalho e o poder ou se é uma construção cultural, ou ainda uma forma de comunicação ampla é necessário aprofundar a sua definição e impactos na Educação Física como campo de conhecimento, incluso pelo fato de não ter sido feita, neste estudo uma análise paradigmática, gnosiológica e ontológica mais específica, o que deve ser realizado em aprofundamento deste estudo posteriormente.

É preciso compreender os motivos da não utilização de uma conceituação teórica, pois, no entendimento que se expressa pelos autores deste artigo, essa diferenciação é relevante por se referir a uma concepção clara e distinta. Ou seja, a CL é aqui entendida como a manifestação, a expressão que é própria do corpo, assim, este termo torna-se mais coerente com uma perspectiva dos elementos constitutivos do próprio corpo em sua expressão de vida, os quais podem se aproximar de uma perspectiva materialista dialética de corpo, pois, o ser humano se mantém por meio do trabalho, entendido por Marx (2011), como uma relação de metabolismo entre o ser humano e a natureza.

\section{REFERÊNCIAS}

ADELMAN, Miriam. Mulheres no esporte: corporalidades e subjetividades. Movimento, v. 12, n. 1, p. 1129, 2006. Disponível em: http://www.redalyc.org/articulo.oa?id=115315943002. Acesso em: 16 fev. 2021.

ADORNO, Theodor W.; HORKHEIMER, Max. Dialética do esclarecimento: fragmentos filosóficos. Rio de Janeiro: Jorge Zahar, 1985.

ALMEIDA, Miguel Vale de. O corpo na teoria antropológica. Revista de Comunicação e Linguagens, v. 33, p. 49-66, 2004. https://edisciplinas.usp.br/pluginfile.php/1884397/mod_resource/content/1/o-corpo-nateoria-antropologica.pdf. Acesso em: 21 jul. 2021 
BARATA, Rita Barradas. Mudanças necessárias na avaliação da pós-graduação brasileira. Interface: comunicação, saúde e educação (Botucatu), v. 23, p. 1-6, 2019.

https://www.scielosp.org/article/icse/2019.v23/e180635/pt/. Acesso em: 05 mar. 2021.

CHRISTO, Carlos Alberto Libânio (Frei BETTO). Políticas do corpo. Motrivivência, n. 15, 2000.

Disponível em: https://periodicos.ufsc.br/index.php/motrivivencia/article/view/5583. Acesso em: 05 mar. 2021.

CODO, W.; SENNE, W.A. O que é corpo (latria). São Paulo: Brasiliense, 1984.

FERREIRA, Antonio Leonan Alves. Estrutura e função social da atividade esportiva e o processo de apropriação da cultura: contribuições para a atividade de ensino na educação física escolar. Motrivivência, v. 30, n. 54, p. 295-307, 2018. Disponível em:

https://periodicos.ufsc.br/index.php/motrivivencia/article/view/2175-8042.2018v30n54p295. Acesso em: 05 mar. 2021

GAMBAROTTA, Emiliano. El cuerpo del postestructuralismo. Problemas epistemológicos a partir de la perspectiva de J. Butler. Revista Brasileira de Ciências do Esporte, v. 39, p. 240-246, 2017. Disponível em: https://www.scielo.br/j/rbce/a/yYH7xKjhn5s6T7Wzc6NLmFq/?lang=es. Acesso em: 16 fev. 2021.

GAMBAROTTA, Emiliano. La sociogénesis del modo de corporalidad moderno. El problema del objeto en las investigaciones sobre cuerpo a partir de la teoría crítica reflexiva. Revista brasileira de Ciências do Esporte, v. 38, p. 194-200, 2016. Disponível em:

https://www.scielo.br/j/rbce/a/kRrrRQKtTw7xSwnVb3fS96q/abstract/?lang=es. Acesso em: 16 fev. 2021.

GRANDO, Beleni Saléte. Corpo e cultura: a educação do corpo em relações de fronteiras étnicas e culturais e a constituição da identidade Bororo em Meruri-MT. Pensar a prática, v. 8, n. 2, p. 163-180, 2005. Disponível em: https://www.revistas.ufg.br/index.php/fef/article/view/112. Acesso em: 16 fev. 2021

MACHADO, Rubens; FAGUNDES, Bruno; SILVA, Fabiano Weber da. As crianças como autoras da significação da educação física. Motrivivência, n. 37, p. 51-68, 2011. Disponível em: https://periodicos.ufsc.br/index.php/motrivivencia/article/view/2175-8042.2011v23n37p51. Acesso em: 08 mar. 2021.

MAFRA, Cláudio. Perfil de produção científica dos docentes em uma instituição federal de ensino superior no Brasil. Revista Brasileira de Pós-Graduação, v. 16, n. 36, p. 1-43, 2020. Disponível em: https://rbpg.capes.gov.br/index.php/rbpg/article/view/1689. Acesso em: 05 mar. 2021.

MARX, Karl. O Capital: crítica da economia política, livro 1: o processo de produção do capital, v. 1. 29. ed. Rio de Janeiro: Civilização Brasileira, 2011.

MARZANO-PARISOLI, Maria M. Pensar o corpo. Petrópolis: Vozes, 2004.

MAUSS, Marcel. Sociologia e Antropologia. 4ª Reimpressão, São Paulo: Cosac Naify, 2013.

MEDINA, João Paulo S. A educação física cuida do corpo... e "mente". 25. ed. rev. e ampl. Campinas: Papirus, 2010.

MEDINA, João Paulo S. O brasileiro e seu corpo: educação e política do corpo. 12. ed. Campinas: Papirus, 2009.

MENDES, K. D. S.; SILVEIRA, R. C. C. P.; GALVÃO, C. M. Revisão integrativa: método de pesquisa para incorporação de evidências na saúde e na enfermagem. Texto Contexto Enferm, v. 17, n. 4, p. 758-64, 
2008. Disponível em: https://www.scielo.br/j/tce/a/XzFkq6tjWs4wHNqNjKJLkXQ/?lang=pt\&format=html. Acesso em: 05 maio 2021.

MOREIRA, Wagner W.; SIMÕES Regina. Corporeidade e formação profissional na área da educação física e dos esportes. In: PACHECO NETO, Manuel (Org.). Desafios da educação física: cultura e corpo em movimento. Dourados - MS: Ed. UFGD, 2016, p.41-56.

MUNARIM, Iracema. O que podemos aprender com as crianças indígenas? Aproximações da antropologia da criança às noções de infância, cultura e movimento na educação física. Revista Brasileira de Ciências do Esporte, v. 33, p. 375-390, 2011. https://www.scielo.br/j/rbce/a/ztQwQQS3nYPK8mXTGgdrv6j/?lang=pt. Acesso em: 16 fev. 2021.

NÓBREGA, Terezinha P. da (Org.). Estesia: corpo e fenomenologia em movimento. São Paulo: LiberArs, 2018.

NÓBREGA, Terezinha P. da. Uma fenomenologia do corpo. São Paulo: Editora e Livraria da Física, 2010.

OLIVEIRA, Marcus A. T. de. Corporalidade. In: GONZÁLES, Fernando J.; FENTERSEIFER, Paulo E. (Orgs.). Dicionário crítico de educação física. 3. ed. rev. e ampl. Ijuí: Editora Unijuí, 2014, p. 153-157.

OLIVEIRA, Marcus Aurélio Taborda de. Existe espaço para o ensino de educação física na escola básica? Pensar a prática, v. 2, p. 119-135, 1999. Disponível em:

https://www.revistas.ufg.br/index.php/fef/article/view/152. Acesso em: 21 jul. 2021.

OLIVEIRA, Marcus Aurélio Taborda de; OLIVEIRA, Luciane Paiva Alves de; VAZ, Alexandre Fernandez. Sobre corporalidade e escolarização: contribuições para a reorientação das práticas escolares da disciplina de educação física. Pensar a prática, v. 11, n. 3, p. 303-303, 2008. Disponível em:

https://www.revistas.ufg.br/index.php/fef/article/view/4344. Acesso em: 21 jul. 2021.

PEREIRA, Rogério Santos; SILVA, Maurício Roberto da; PIRES, Giovani de Lorenzi. Representações de corpo e movimento no ciberespaço: notas de um estudo etnográfico no jogo Second Life. LICERE-Revista do Programa de Pós-graduação Interdisciplinar em Estudos do Lazer, v. 12, n. 2, p. 1-23, 2009.

Disponível em: https://periodicos.ufmg.br/index.php/licere/article/view/874. Acesso em: 05 mar. 2021.

PIRES, H. et al. Braga, snapshots in virtual reality: Do sentir ao pensar. In H. Pires \& Z. Pinto-Coelho (Eds.), Transartes, arte expandida e novas linguagens. Minho: CECS, 2021, p. 101-130.

SANTIN, Silvino. Coporeidade. In: GONZÁLES, Fernando J.; FENTERSEIFER, Paulo E. (Orgs.). Dicionário crítico de educação física. 3. ed. rev. e ampl. Ijuí: Editora Unijuí, 2014, p. 157-158.

SANTIN, Silvino. Educação física: uma abordagem filosófica da corporeidade. 2. ed. rev. Ijuí: UNIJUÍ, 2003.

SILVA, Ana Márcia; SILVA, Ana Paula S. da; TUCUNDUVA, Tatiana. Corpo, cultura e natureza em terras quilombolas. In: SILVA, Ana Márcia; FALCÃO, José Luiz Cirqueira (Org.). Práticas corporais em comunidades Quilombolas de Goiás. Goiânia: Ed. da PUC Goiás, 2011, p. 47-75.

SOARES, Marta Genu; KANEKO, Glaucia Lobato; GLEYSE, Jacques. Do porto ao palco, um estudo dos conceitos de corporeidade e corporalidade Dialektiké, IFRN, v. 3, n. 2, pp.66-75, 2015. Disponível em: https://hal.archives-ouvertes.fr/hal-01334283/document. Acesso em: 27 dez. 2019.

ZOBOLI, Fábio. Cisão corpo mente: espelhos e reflexos na práxis da educação física. São Cristóvão: Editora da UFS, 2012. 


\section{NOTAS DO AUTOR}

AGRADECIMENTOS - Não se aplica.

CONTRIBUIÇÃO DE AUTORIA - Não se aplica.

FINANCIAMENTO - Não se aplica.

CONSENTIMENTO DE USO DE IMAGEM - Não se aplica.

APROVAÇÃO DE COMITÊ DE ÉTICA EM PESQUISA - Não se aplica.

\section{CONFLITO DE INTERESSES}

Não há conflito de interesses por parte de nenhuma das pessoas da autoria.

\section{LICENÇA DE USO}

Os autores cedem à Motrivivência - ISSN 2175-8042 os direitos exclusivos de primeira publicação, com o trabalho simultaneamente licenciado sob a Licença Creative Commons Attribution Non-Comercial ShareAlike (CC BY-NC SA) 4.0 International. Esta licença permite que terceiros remixem, adaptem e criem a partir do trabalho publicado, desde que para fins não comerciais, atribuindo o devido crédito de autoria e publicação inicial neste periódico desde que adotem a mesma licença, compartilhar igual. Os autores têm autorização para assumir contratos adicionais separadamente, para distribuição não exclusiva da versão do trabalho publicada neste periódico (ex.: publicar em repositório institucional, em site pessoal, publicar uma tradução, ou como capítulo de livro), com reconhecimento de autoria e publicação inicial neste periódico, desde que para fins não comerciais e compartilhar com a mesma licença.

\section{PUBLISHER}

Universidade Federal de Santa Catarina. Programa de Pós-Graduação em Educação Física. LaboMídia - Laboratório e Observatório da Mídia Esportiva. Publicado no Portal de Periódicos UFSC. As ideias expressadas neste artigo são de responsabilidade de seus autores, não representando, necessariamente, a opinião dos editores ou da universidade.

\section{EDITORES}

Mauricio Roberto da Silva, Giovani De Lorenzi Pires, Rogério Santos Pereira.

\section{EDITOR DE SEÇÃO}

Silvan Menezes dos Santos

\section{REVISÃO DO MANUSCRITO E METADADOS}

Juliana Rosario; Keli Barreto Santos.

\section{HISTÓRICO}

Recebido em: 31 de agosto de 2021.

Aprovado em: 08 de novembro de 2021. 